\title{
A single-center audit of the indications and clinical impact of prolonged ambulatory small intestinal manometry
}

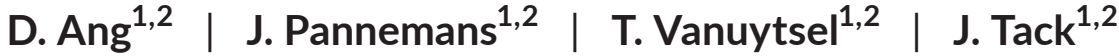

\author{
${ }^{1}$ Translational Research Center \\ for Gastrointestinal Disorders \\ (TARGID), Department of Chronic \\ Diseases, Metabolism and Aging, KU Leuven, \\ Leuven, Belgium \\ ${ }^{2}$ Division of Gastroenterology, University \\ Hospitals, Leuven, Belgium

\section{Correspondence} \\ Jan Tack, MD, PhD, Translational Research \\ Center for Gastrointestinal Disorders \\ (TARGID), Department of Chronic Diseases, \\ Metabolism and Aging, Leuven, Belgium. \\ Email: jan.tack@med.kuleuven.be \\ Funding information \\ JT has received funding from the \\ Methusalem grant from Leuven University.
}

\begin{abstract}
Background: Small bowel manometry is a diagnostic test available only in a few specialized referral centers. Its exact place in the management of refractory symptoms is controversial.

Methods: The records of all patients who underwent 24-hour ambulatory duodenojejunal manometry over a 6-year period were retrospectively reviewed. We studied the clinical indications for small bowel manometry, and reviewed the impact of manometric findings on the clinical outcome. One hundred and forty-six studies were performed in 137 patients $(46 \mathrm{M}, 91 \mathrm{~F})$ with a mean age of $44.9 \pm 15.7$ years. Mean follow-up duration was $15.1 \pm 22.6$ months. Appropriate endoscopic, radiological and gastric scintigraphy studies were performed in all patients prior to small bowel manometry. Criteria for abnormal motor activity were based on Bharucha's classification.

Key Results: The indications for small bowel manometry were chronic abdominal pain $(n=43)$, slow-transit constipation $(n=17)$, refractory gastroparesis $(n=16)$, chronic diarrhea $(n=7)$, recurrent episodes of subocclusion $(n=16)$, postsurgical evaluation ( $n=36)$, suspicion of gut involvement in systemic disease $(n=9)$, and unexplained nausea $(n=2)$. The most common finding was a normal 24-hour ambulatory small bowel manometry $(n=113)$. Thirty-three studies yielded abnormal findings which included extrinsic neuropathy $(n=6)$, intrinsic neuropathy $(n=18)$, intestinal myopathy $(n=2)$, and subocclusion $(n=7)$. Ambulatory small bowel manometry excluded a generalized motility disorder in $77 \%$ and had a significant impact on the subsequent clinical course in $23 \%$.

Conclusions \& Inferences: Ambulatory small bowel manometry is a useful and safe diagnostic tool to complement traditional investigative modalities in patients with severe unexplained abdominal symptoms.
\end{abstract}

\section{KEYWORDS}

myopathy, neuropathy, small bowel motility, small intestinal manometry

\section{1 | INTRODUCTION}

The technique of small bowel manometry is a diagnostic modality, which is only available in a few specialized referral centers. Through intraluminal measurement techniques, insight is obtained in gastrointestinal (GI) physiology and pathophysiology motility disorders. ${ }^{1}$ In the fasting state, the motility of the stomach and small intestine is characterized by a cyclic pattern of contractions, the migrating motor complex (MMC). ${ }^{2}$ The first detailed description of the MMC by Szurszewski et al. ${ }^{2}$ in 1969 of intestinal MMCs in dogs 
paved the way for numerous studies of the physiological and pathophysiological significance of the MMC. His findings on the MMC pattern were confirmed in man in 1977 by Vantrappen et al. ${ }^{3}$ who also reported that absence of $\mathrm{MMC}$ was an important risk factor for bacterial overgrowth in humans, establishing an important role for the $\mathrm{MMC}$ as intestinal housekeeper and regulator of interdigestive flow. $^{4}$

Small bowel motility can be recorded by manometry ${ }^{5}$ and by various transit tests. ${ }^{6-8}$ While stationary manometry with the use of external transducers and water perfused tubes was frequently applied in the past, ${ }^{9-13}$ the establishment ${ }^{14}$ and implementation of ambulatory techniques ${ }^{15-18}$ have allowed continuous ambulatory readings during day and night. Due to prolonged recordings with solid-state systems, response to meals and diurnal variation in motor activity can be assessed, allowing more adequate evaluation of interdigestive motility abnormalities. ${ }^{19}$ In addition, nocturnal recordings are helpful in defining phase 3 activity of the $M M C^{20}$ and provide important data used to form a more accurate diagnosis. ${ }^{21-23}$ Although specific diseases cannot be diagnosed by small bowel manometry alone, it allows for an assessment of the functional integrity of the bowel. $^{20,24,25}$

Evaluation of patients thought to have a small bowel motility disorder has been performed with either stationary small bowel manometry (range of 6-8 hours) ${ }^{26-32}$ or prolonged ambulatory recording (range of 16-72 hours) in a number of studies to date. ${ }^{18,20,23,31,33-44}$ However, since the last report ${ }^{44}$ in 2009, largescale studies on the clinical utility of prolonged ambulatory monitoring are lacking.

The aim of this study was to evaluate the role of ambulatory small bowel manometry in clinical management. For this purpose, we conducted a retrospective analysis of the indications, manometric findings and clinical impact of all 24-hour ambulatory small bowel manometry studies performed at the University Hospitals Leuven, Belgium over a 6-year period. A reappraisal of this diagnostic modality is timely today, more than 30 years since the first reported study. ${ }^{45}$ In line with technological advances in catheter design, transducer device and recording software, prolonged ambulatory small intestinal manometry is now performed with increasing ease. To our knowledge, our study represents the largest series of patients undergoing 24-hour ambulatory small bowel manometry at a tertiary referral center reported to date.

\section{2 | MATERIALS AND METHODS}

\section{1 | Subjects}

We performed a retrospective review of all small bowel manometry studies performed by the Department of Gastroenterology at the University Hospitals Leuven, Belgium over a 6-year period. Case records were reviewed and data extracted for patient demographics, clinical history, investigations performed and outcome after small bowel manometry. We evaluated 137 consecutive patients (46 males, 91 females, mean age $44.9 \pm 15.7$ years, age range 14-79). The patients were referred to our center for further evaluation of symptoms suggestive of intestinal dysmotility. In addition to routine clinical examination and appropriate blood chemistry, the diagnostic evaluation generally included endoscopy, abdominal imaging as computed-tomography/ultrasound, small bowel radiology, breath tests for bacterial overgrowth and gastric emptying studies where appropriate. Mechanical bowel obstruction and other organic or anatomical lesions were excluded prior to small bowel manometry evaluation. Informed consent was obtained from all patients prior to small bowel manometry, and the Ethics Committee of the hospital previously approved the study.

\section{2 | Recording technique}

Recordings of duodenal and jejunal intraluminal pressures were performed using a $250-\mathrm{cm}$-long silicone catheter (OD $4 \mathrm{~mm}$ ) with 6 solid-state pressure transducers (Konigsberg Instruments, Pasadena, CA, USA) mounted on it. A second single-lumen catheter with a latex bag at its end that could be filled with air was attached to the silicone catheter to accelerate the passage of the probe until correct positioning was achieved. Calibration of the pressure sensors was performed in a pneumatic chamber at room temperature. The probe was introduced orally and positioned under fluoroscopic control in such a way that the proximal first group of 3 sensors, which were $4 \mathrm{~cm}$ apart, was located in the descending part of the duodenum. The other group of 3 sensors, which were also $4 \mathrm{~cm}$ apart, was located in the jejunum with the first sensor of this group being $30 \mathrm{~cm}$ distal to the last sensor of the first group of 3 sensors. After correct positioning, the latex bag was deflated and the probe connected to a portable digital recording device (Digitrapper, Synectics, Sweden). The Digitrapper had an internal memory of four megabytes. The sampling frequency used was $4 \mathrm{~Hz}$ for each of the 6 recording channels, which is suitable for accurate reproduction of analog motility signals. ${ }^{15}$ Endoscopic guided insertion of the manometry catheter was utilized in cases where pyloric intubation through the pylorus was unsuccessful.

\section{3 | Study design}

At least 72 hours before the study, patients were instructed to stop any medication known to affect GI motility. Patients were admitted to hospital for the purpose of the 24-hour small bowel manometry study. Following an overnight fast of at least 12 hours, the recording probe was introduced as described above and secured to the subject's nose with adhesive tape. The subjects were asked to ingest 2 standardized meals of equal caloric load $(800 \mathrm{kcal}$; meatloaf, mashed potatoes and apple sauce) and chemical composition (40\% fat, $45 \%$ carbohydrates, $15 \%$ protein). One meal was administered around 12 noon, the second meal between 5 and 6 PM. Subjects were not allowed to eat or drink anything else but water during the study. They were fully ambulant during the study, but were asked to refrain from smoking or vigorous exercise. Subjects were provided a diary 


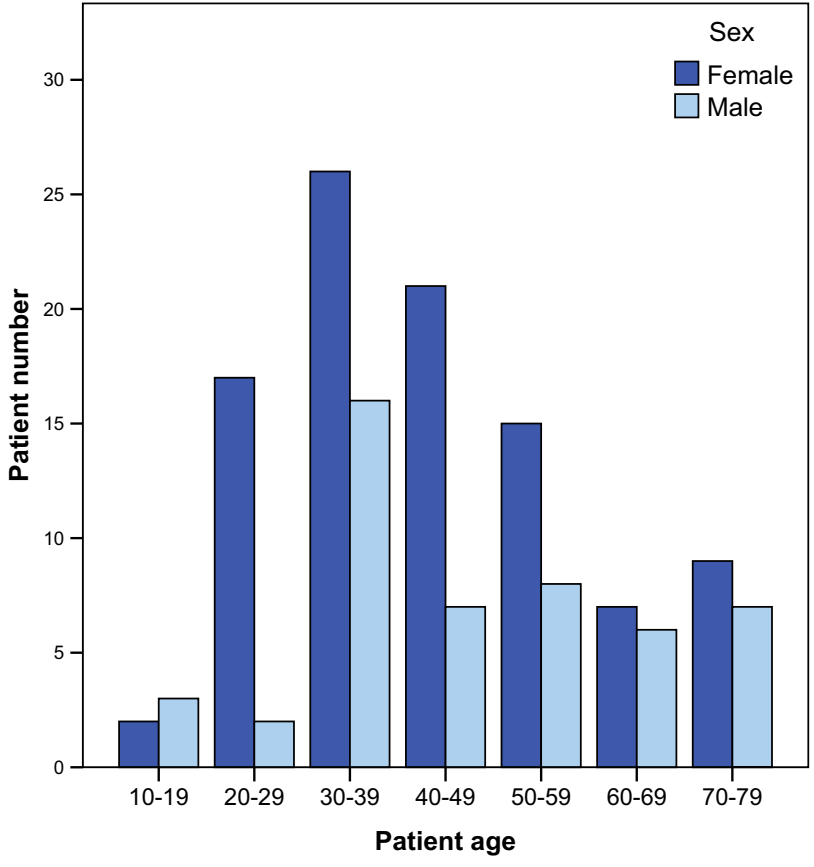

FIGURE 1 Age distribution of patients in the study

to record meal times, as well as the times during upright and supine position.

\subsection{Analysis of motility parameters}

At the end of the 24-hour study, the data stored in the Digitrapper were downloaded to a personal computer for visual display and analysis. Recordings of duodenojejunal motor activity were analyzed visually. Results were compared with studies in healthy controls done in our center previously. ${ }^{42}$ Pressure changes $<5 \mathrm{~mm} \mathrm{Hg}$ and identifiable artifacts were excluded from analysis. Criteria for abnormal motor activity were based on the classification proposed by Bharucha et $\mathrm{al}^{30}$ and data collected previously from our center. ${ }^{42}$ Patterns of activity were classified as follows:

1. Normal pattern: normal MMC activity in small bowel with normal fed response.

2. Intestinal myopathy: characterized by decreased amplitude of contractile activity but preserved normal organization of motor activity.

3. Extrinsic (autonomic) neuropathy: characterized by lack of response to a meal and failure to establish a fed pattern of motility.

4. Intrinsic (enteric) neuropathy: characterized by contractile activity of normal amplitude but abnormal configuration and migration pattern of phase III of the $M M C$, including retrograde propagation, simultaneous occurrence and/or absence of a phase III over a 24 -hour period.

5. Patterns suggestive of intestinal obstruction, such as prolonged clustered contractions in the postprandial period or long bursts of phasic activity.
Bursts were defined as periods of $\geq 2$-minute duration with continuous high amplitude ( $\geq 20 \mathrm{~mm} \mathrm{Hg}$ ) and high frequency (10-12/min) phasic pressure activity that were not propagated and not followed by motor quiescence. Clusters of clinical significance were defined as an uninterrupted sequence of at least 3 rhythmic contractions that was not a component of a phase III of the MMC and was separate from the next motor event by a quiescent period of at least 5 seconds duration, and which was identified in at least 2 jejunal sensors, and lasting for a threshold of at least 20 minutes. ${ }^{22}$ The subsequent analysis was done with a computer program previously developed and validated in our unit and described in detail elsewhere. ${ }^{46}$

We considered the clinical impact of ambulatory small bowel manometry as clinically relevant when one of the following conditions was fulfilled:

1. Confirmation of a clinical suspicion of a motility disorder, resulting either in a definitive diagnosis or the need for a diagnostic surgical procedure.

2. Exclusion of a generalized motility disorder as part of preoperative evaluation in patients considered for surgery.

3. Determination of extent of motility disorder in the presence of a systemic disease, such as diabetes mellitus.

4. Influence on the decision to start total parenteral nutrition (TPN). This is based on a single study suggesting that the outcome of motility studies might determine need for TPN. ${ }^{24}$

In addition, we analyzed the charts for other motility tests (mainly gastric emptying tests and ${ }^{14} \mathrm{CO}_{2}$ - glycylcholate breath test for bacterial overgrowth. ${ }^{47,48}$

\section{3 | RESULTS}

\section{1 | Patient information}

One hundred and thirty-seven patients $(46 \mathrm{M}, 91 \mathrm{~F})$ with a mean age of $44.9 \pm 15.7$ years (range 14-79) underwent 146 studies. The patient age and sex distribution are illustrated in Figure 1. Eight patients underwent a repeat study. Mean recording time was $21.3 \pm 3.2$ hours $(10.6 \pm 6.3$ hours during the day and $10.7 \pm 5.8$ hours during the nighttime). Five (3.6\%) patients required endoscopy in order to advance the catheter through the pylorus. All except 1 patient tolerated the entire duration of the study.

\section{2 | Indications for manometry}

The predominant indications for performing small bowel manometry are summarized in Table 1 . The most common indications were unexplained chronic abdominal pain in 43 patients (29.5\%) and postsurgical evaluation in 36 patients (24.7\%) with symptoms suggestive of dysmotility. The postoperative studies were performed in patients who had undergone either partial $(n=11)$ or total $(n=12)$ gastrectomy, previous small bowel resection $(n=5)$, previous Nissen 
TAB LE 1 Summary of the indications for ambulatory small intestinal manometry

\begin{tabular}{|lc|}
\hline Indications & No (\%) \\
\hline Chronic abdominal pain & $43(29.5)$ \\
\hline Slow-transit constipation & $17(11.6)$ \\
\hline Refractory gastroparesis & $16(11)$ \\
\hline Chronic diarrhea & $7(4.8)$ \\
\hline Subocclusion & $16(11)$ \\
\hline Unexplained abdominal symptoms after surgery & $36(24.7)$ \\
\hline $\begin{array}{l}\text { Evaluate for presence of gastrointestinal } \\
\text { involvement in systemic disease }\end{array}$ & $9(6.2)$ \\
\hline Unexplained nausea & $2(1.4)$ \\
\hline
\end{tabular}

fundoplication ( $n=2)$, and 6 patients who had undergone bariatric surgery.

\subsection{Findings on small intestinal manometry}

The most common finding was a normal 24-hour ambulatory small bowel manometry, as reported in 113 studies (77.4\%), illustrated in Table 2 together with the abnormal findings classified by the clinical indications for the study. In the patients, with unexplained nausea and chronic constipation, in this series, the small bowel manometry did not have an impact on the treatment choice. Thirty-three (22.4\%) studies yielded abnormal findings which included findings suggestive of extrinsic neuropathy (6 studies), of intrinsic neuropathy (18 studies), of intestinal myopathy (2 studies) and of mechanical subocclusion (7 studies).

\subsection{Clinical impact}

Table 3 summarizes the clinical impact for performing manometry classified by clinical indication.

\subsection{1 | Confirmation of a clinical suspicion of a motility disorder, resulting in either a definitive diagnosis or the need for a diagnostic surgical procedure}

The most significant impact of small bowel manometry lies in its ability to document motility abnormalities that are not detected by other non-invasive radiological imaging or nuclear scintigraphy techniques. This is especially important in unraveling motor disorders that result in functional obstruction. One example are patients with a previous Roux-en-Y gastroenterostomy, developing the so-called Roux syndrome with retrograde propagation of motility in the afferent jejunal limb due to an inversion of the slow wave gradient. ${ }^{27,49}$ Symptoms suggestive of this syndrome include postprandial abdominal pain, bloating, nausea, and vomiting attributed to a functional obstruction within the Roux limb caused by motor asynchrony. ${ }^{27}$ In the absence of a structural obstruction, small bowel manometry remains the only modality to clearly identify abnormal motility patterns in these subjects.

We confirmed the clinical suspicion of Roux-en-Y syndrome in 3 patients. We were able to identify this syndrome through retrograde phase $3 \mathrm{~s}$, consistent with a diagnosis of Roux-en-Y syndrome. Figure 2 illustrates these manometric features in 1 patient.

A decision for diagnostic laparoscopy and full thickness intestinal biopsy was made in 5 patients with recurrent episodes of small intestinal subocclusion and features of intrinsic neuropathy on manometry. Intestinal biopsy confirmed presence of myenteric ganglionitis in 2 of 5 patients who underwent open biopsy.

\subsection{2 | Exclusion of a generalized motility disorder as part of preoperative evaluation in patients considered for surgery}

Prior to definitive surgery, manometry was performed to exclude a generalized motility disorder in 9 subjects. Following a normal

TAB LE 2 Summary of manometry findings obtained from 24-hour ambulatory small intestinal manometry, according to the Bharucha's classification. $^{30}$

\begin{tabular}{|c|c|c|c|c|c|}
\hline & Normal & $\begin{array}{l}\text { Myopathy } \\
\text { pattern }\end{array}$ & $\begin{array}{l}\text { Extrinsic } \\
\text { neuropathy }\end{array}$ & Intrinsic neuropathy & Clustering \\
\hline Chronic abdominal pain & 40 & & & 2 (prolonged simultaneous contractions) & 1 \\
\hline Slow-transit constipation & 14 & & & 1 (prolonged simultaneous contractions) & 2 \\
\hline Refractory gastroparesis & 13 & & & 2 (hypomotility) & 1 \\
\hline Chronic diarrhea & 5 & & & $\begin{array}{l}1 \text { (bursts and absence of phases 3), } 1 \text { (intestinal } \\
\text { hypermotility with high amplitude phases } 3 \text { ) }\end{array}$ & \\
\hline Subocclusion & 8 & & 1 & $\begin{array}{l}2 \text { (absent phase } 3 \text { ), } 1 \text { (bursts with abnormally propagated } \\
\text { phase 3), } 3 \text { (severe intestinal hypomotility) }\end{array}$ & 1 \\
\hline $\begin{array}{l}\text { Unexplained abdominal } \\
\text { symptoms after surgery }\end{array}$ & 24 & 2 & 4 & 3 (Retrograde phases 3), 1 (severe hypomotility) & 2 \\
\hline $\begin{array}{l}\text { Evaluate for presence of } \\
\text { gastrointestinal involve- } \\
\text { ment in systemic disease }\end{array}$ & 7 & & 1 & 1 (absent phase 3 ) & \\
\hline Unexplained nausea & 2 & & & & \\
\hline Total & 113 & 2 & 6 & 18 & 7 \\
\hline
\end{tabular}


TAB LE 3 Summary of clinical impact of small bowel manometry classified by clinical indication

\begin{tabular}{|c|c|c|c|c|}
\hline & $\begin{array}{l}\text { Confirm motility } \\
\text { disorder }\end{array}$ & Preoperative evaluation & $\begin{array}{l}\text { Gl involvement in } \\
\text { systemic disease }\end{array}$ & $\begin{array}{l}\text { Influence } \\
\text { decision for TPN }\end{array}$ \\
\hline Chronic abdominal pain & & & 9 & 1 \\
\hline Slow-transit constipation & & 3 & & \\
\hline Refractory gastroparesis & 1 & 1 & & 3 \\
\hline Subobstruction & 3 & 1 & & 3 \\
\hline $\begin{array}{l}\text { Unexplained abdominal } \\
\text { symptoms after surgery }\end{array}$ & 5 & 4 & & 9 \\
\hline Total & 9 & 9 & 9 & 16 \\
\hline
\end{tabular}

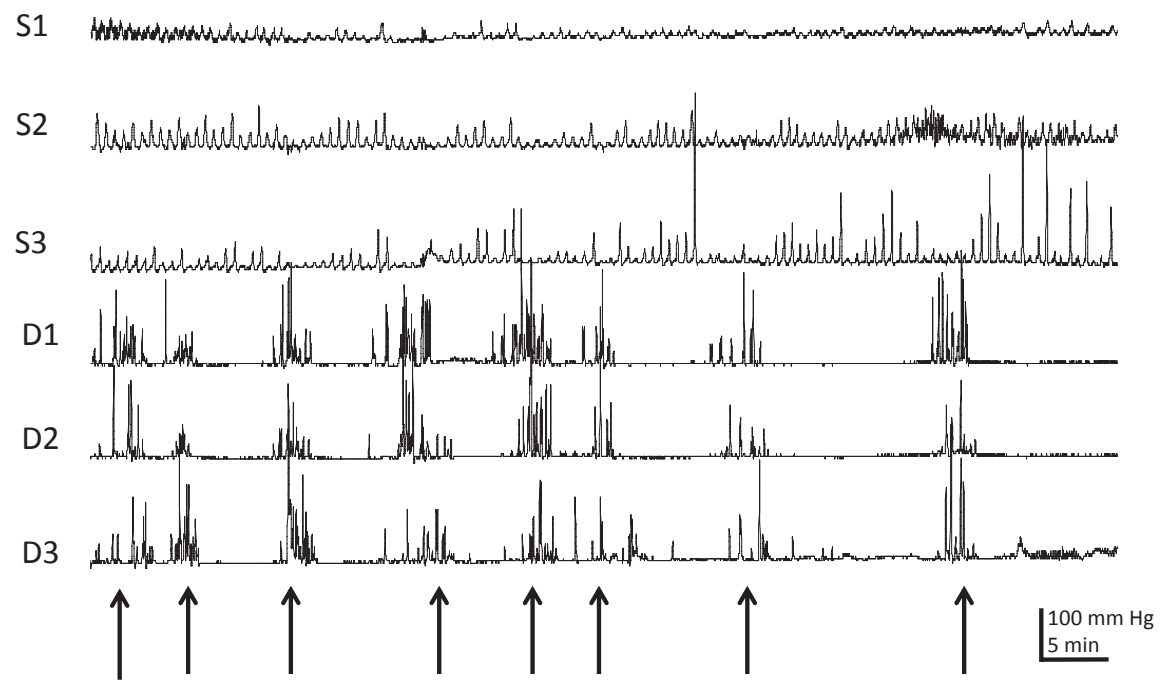

FIGURE 2 Illustration of clustered contractions in the small bowel. Manometry sites in the stomach (S1-3) and the duodenum (S1-3). The arrows indicate clustered contractions. The sensors were $4 \mathrm{~cm}$ apart

study, a subtotal colectomy for slow-transit constipation (STC) was performed in 3 subjects, surgical correction of superior mesenteric artery syndrome in 1 subject; a venting ileostomy in 1 patient with recurrent episodes of subacute small bowel subocclusion, and conversion of prior Bilroth I to a Bilroth II gastrectomy in 4 subjects.

\subsection{3 | Determination of extent of motility disorder in the presence of a systemic disease, such as diabetes mellitus}

Seven patients with diabetes mellitus and 2 patients with scleroderma who presented with recurrent symptoms of abdominal pain and vomiting underwent small intestinal manometry to evaluate the extent of $\mathrm{Gl}$ involvement. We documented failure of the fed response in the postprandial phase in 1 patient with diabetes mellitus, consistent with an extrinsic (autonomic) neuropathy. In contrast, 1 patient with scleroderma showed presence of a normal fed response in the day time but disrupted MMCs and complete absence of nocturnal phase $3 \mathrm{~s}$ lending support to an enteric (intrinsic) neuropathy.

\subsection{4 | Influence decision for TPN}

The role of manometry in predicting response to feeding in adults has not been well studied. One previous study has shown that abnormal jejunal motility is an important predictor of intolerance to tube feeding in the postoperative period. ${ }^{24} \mathrm{~A}$ total of 16 patients in our series received TPN. Table 4 summarizes the patients' symptoms who received enteral and parenteral feeding. However, a normal or abnormal outcome on small bowel manometry did not directly influence the decision to start TPN or not. In fact, it seemed that this was mainly determined by the general wellbeing and ability to eat by the patient, and the outcome of manometry did not help this decision.

The most common finding was a normal study in 113 studies (77\%). These studies were predominantly performed in patients who had recurrent episodes of unexplained abdominal pain, for whom prior extensive investigations either conducted at our hospital or by the referring center were inconclusive. In these patients, a normal small bowel manometry complemented extensive prior diagnostic investigations and provided reassurance for both the patients and the referring physicians. Table 5 shows the manometric findings in patients who received enteral and parenteral feeding. 


\begin{tabular}{lcc} 
Subgroup & PEG/PEJ & TPN \\
\hline Chronic abdominal pain & 1 & 1 \\
\hline Gastroparesis & 5 & 3 \\
\hline Subocclusion & 1 & 3 \\
\hline Unexplained abdominal symptoms after surgery & 7 & 9 \\
\hline Total & 14 & 16 \\
\hline
\end{tabular}

TABLE 4 Summary of patients who received enteral and parenteral feeding

\section{5 | Correlation between other investigations}

The available diagnostics that were additionally or precedingly performed in this patient series did not correlate with the outcome of the small bowel manometry results. A Spearman correlation coefficient was calculated for the available other motility diagnostics. The gastric emptying of solids $(n=88)$ and liquids $(n=69)$ showed a correlation coefficient of $-.07(P=.52)$ and $-.067(P=.59)$, respectively, both non-significant. The bile acid breath tests $(n=61)$, which we use to diagnose bacterial overgrowth, correlation coefficient was $.25(P=.054)$ and was borderline non-significant.

\section{4 | DISCUSSION}

Almost a decade was required for small bowel manometry to pass from the confines of the research laboratory to its role as a clinical diagnostic tool. ${ }^{5}$ In comparison to previous small bowel manometric studies, our study provides the largest number of patients who underwent a 24-hour ambulatory small bowel manometry at a single center to date.

From a clinical perspective, the status of small bowel manometry remains uncertain, although it is being used as a valid diagnostic tool in a number of specialized centers. The ambiguity lies in the invasive nature of the test, the need for dedicated equipment and considerable expertise with limited available therapeutic options. Adequate catheter placement is challenging in patients who may have functional gastric outlet obstruction. ${ }^{28}$ It is therefore not surprising that it cannot be recommended as a single investigative modality for the diagnosis of functional dyspepsia or irritable bowel syndrome. ${ }^{50}$ In our series, only 5 patients required endoscopic catheter insertion in order to advance the catheter through the pylorus. However, despite the invasiveness of this test, it is generally well-tolerated,

TAB LE 5 Manometric findings in patients who received enteral and parenteral feeding

\begin{tabular}{lcc|}
\hline Manometric findings & PEG/PEJ & TPN \\
\hline Normal & 11 & 8 \\
\hline Myopathy & 0 & 2 \\
\hline Extrinsic neuropathy & 1 & 1 \\
\hline Intrinsic neuropathy & 2 & 5 \\
\hline Total & 14 & 16 \\
\hline
\end{tabular}

as confirmed in our study, where $99 \%$ of patients tolerated the full 24 hours of the study.

Abnormalities of small bowel manometry are non-specific, with considerable overlap between health, disease and in between diseases $^{31,40,44,50}$ as illustrated by the presence of clustered contractions in both diarrhea-predominant IBS and healthy controls ${ }^{33,51}$ or the presence of the MMC in normal transit constipation and STC. ${ }^{44}$ There are also interpatient and intrapatient differences in measurements. ${ }^{43}$ In addition, it is important to note the imperfect correlation between clinical symptoms and physiological measurements for motility disorders. ${ }^{40,52,53}$ This may be due to symptoms caused by abnormalities in segments of the small bowel not studied, such as abnormal tonic contractions in the ileum in patients with IBS. ${ }^{54}$ The discrepancy between subjective symptoms and objective findings contributes to the challenge of treating motility disorders, reinforcing the important role of clinical judgement in the decision making process. To analyze the qualitative values and aid in this decision making process, healthy volunteer studies have been performed by Soffer et al. ${ }^{43}$ and Scott et al. ${ }^{21}$

To review our experience, we focused on the clinical utility of small bowel manometry, rather than on the actual sensitivity and specificity of various manometric findings in different subgroups of patients with gastrointestinal motility disorders. This approach was also used in studies by Bryne et al. ${ }^{20}$, Soffer et al. ${ }^{37}$ and by Lindberg et al. ${ }^{31}$ The confident exclusion of a generalized GI motility disorder in patients, with prior extensive evaluation and negative findings, occurred in $75 \%$ of our study population. This is reassuring for patients, whose quality of life may be impaired by the severity of their symptoms and the uncertainties of their diagnosis. ${ }^{24}$ As described by Lindberg et al., all patients with chronic intestinal pseudo-obstruction (CIPO) had abnormal small bowel motor activity. ${ }^{31}$ For physicians dealing with such difficult cases, a normal finding is convincing, and helps to redirect therapeutic options away from severe intestinal disorders and may help to consider other possibilities, such as underlying psychological disorders ${ }^{10,24}$ or functional bowel disorders, although small bowel manometry is no routine diagnostic test for these diseases. ${ }^{31,55}$ In patients with idiopathic STC, a normal preoperative small bowel manometry is an accurate predictor of long-term outcome after colectomy. ${ }^{41}$ In addition, the pharmacological effects of drugs ${ }^{56,57}$ or pathophysiology of disorders ${ }^{58}$ can be investigated.

Yet another crucial role of small bowel manometry lies in its ability to demonstrate a functional obstruction in the absence of a mechanical obstruction on radiological imaging as illustrated by our 3 patients who were diagnosed with Roux-en-Y syndrome. Motility 
disturbances in the Roux limb have been widely reported previously. ${ }^{49,59,60}$ As shown in our study and similar to previous studies, retrograde propagating waves were consistently present.

Two patients in our series had manometric features of severe hypomotility and low amplitude phasic waves. Following diagnostic laparoscopy and full thickness intestinal biopsy, a diagnosis of myenteric ganglionitis was made, indicating a neuropathic rather than a myopathic underlying abnormality. The manometric findings, pointing in the direction of a myopathy, did not seem to correlate with the pathology findings in the biopsy. Similarly, Lindberg et al. reported that manometric findings could not differentiate between myopathic or neurogenic disorders. ${ }^{31} \mathrm{~A}$ recent study of Malagelada et al., in which the myopathic manometry pattern did not correlate with signs of enteric myopathy on histopathology, with similar results for neuropathic manometry patterns and their histopathology, confirms this finding. ${ }^{61}$ Despite the varied clinical presentation of CIPO and the different manometric findings described in the literature, the usefulness of manometry lies in its ability to demonstrate proof of generalized gastrointestinal (GI) dysmotility in a patient.

We report an important role of ambulatory small bowel manometry in carefully selected patients, based on our experience at a single center over a 6-year period. Our studies were performed, in a tertiary motility center over a long period in time, in a highly selected group of patients, who underwent this investigation only after prior extensive clinical evaluation had been performed. It is not advised performing small bowel manometry in all patients with chronic abdominal pain. It is undeniable that selection bias may well have accounted for the relatively high clinical yield. Acknowledging these limitations of small bowel manometry, we do not recommend the widespread application of small bowel manometry in daily routine clinical practice. Its use should even be restricted to referral centers where experiences can be gained concerning these motility disorders. Rather, our study reinforces the clinical value of this diagnostic tool in carefully selected instances. Patients should only be referred for this test after extensive imaging to rule out obvious mechanical factors, and only in case of debilitating symptoms (eg, inability to maintain adequate oral nutrition intake) or additional indications of a potential major motility disorder (dilated loops on imaging, visible distention or visible peristalsis upon clinical examination, previous surgery like for instance Roux-en-Y). Small intestinal motility disorders remain a relatively under investigated area. ${ }^{62}$ Hence, the continued use of small bowel manometry will provide further insight into the pathogenesis of these complex disorders.

As in other parts of the GI tract, small bowel manometry is now also moving to high-resolution catheter use. ${ }^{63-65}$ We anticipate that this may lead to improved understanding of underlying pathophysiological mechanisms, but future analysis will reveal whether it improves diagnostic yield and whether it impacts on therapy choices.

\section{ACKNOWLEDGMENT}

None.

\section{DISCLOSURE}

None of the authors has any competing interests that are relevant to the manuscript.

\section{AUTHOR CONTRIBUTION}

JT designed the study; DA acquired the data and analyzed the data; DA and JP drafted the manuscript; TV and JT critically reviewed the manuscript. All authors approved the final version.

\section{REFERENCES}

1. Camilleri M, Bharucha AE, di Lorenzo C, et al. American Neurogastroenterology and Motility Society consensus statement on intraluminal measurement of gastrointestinal and colonic motility in clinical practice. Neurogastroenterol Motil. 2008;20:1269-1282.

2. Szurszewski JH. A migrating electric complex of canine small intestine. Am J Physiol. 1969;217:1757-1763.

3. Vantrappen G, Janssens J, Hellemans J, Ghoos Y. The interdigestive motor complex of normal subjects and patients with bacterial overgrowth of the small intestine. J Clin Invest. 1977;59:1158-1166.

4. Code CF, Schlegel JP. The gastrointestinal housekeeper motor correlates of the interdigestive myoelectric complex of the dog. In: Daniel EE, ed. Proceedings from the Fourth International Symposium on Gastrointestinal Motility. Vancouver, BC: Mitchell Press Ltd; 1974:631-634.

5. Camilleri M. Study of human gastroduodenojejunal motility. Applied physiology in clinical practice. Dig Dis Sci. 1993;38:785-794.

6. Malagelada JR, Robertson JS, Brown ML, et al. Intestinal transit of solid and liquid components of a meal in health. Gastroenterology. 1984;87:1255-1263.

7. Read NW, Al-Janabi MN, Bates TE, et al. Interpretation of the breath hydrogen profile obtained after ingesting a solid meal containing unabsorbable carbohydrate. Gut. 1985;26:834-842.

8. Camilleri M, Zinsmeister AR, Greydanus MP, Brown ML, Proano $M$. Towards a less costly but accurate test of gastric emptying and small bowel transit. Dig Dis Sci. 1991;36:609-615.

9. Camilleri M. Perfused tube manometry. In: Kumar D, Wingate DL, eds. An Illustrated Guide to Gastrointestinal Motility, 2nd edn. Edinburgh: Churchill Livingstone; 1993:183-199.

10. Malagelada JR, Stanghellini V. Manometric evaluation of functional upper gut symptoms. Gastroenterology. 1985;88(5 Pt 1):1223-1231.

11. Stanghellini V, Camilleri M, Malagelada JR. Chronic idiopathic intestinal pseudo-obstruction: clinical and intestinal manometric findings. Gut. 1987;28:5-12.

12. Bassotti G, Pelli MA, Morelli A. Duodenojejunal motor activity in patients with chronic dyspeptic symptoms. J Clin Gastroenterol. 1990;12:17-21.

13. Stanghellini V, Ghidini C, Maccarini MR, Paparo GF, Corinaldesi R, Barbara L. Fasting and postprandial gastrointestinal motility in ulcer and non-ulcer dyspepsia. Gut. 1992;33:184-190.

14. Thompson DG, Wingate DL, Archer L, Benson MJ, Green WJ, Hardy RJ. Normal patterns of human upper small bowel motor activity recorded by prolonged radiotelemetry. Gut. 1980;21:500-506.

15. Lindberg G, Iwarzon M, Stal P, Seensalu R. Digital ambulatory monitoring of small-bowel motility. Scand J Gastroenterol. 1990;25:216-224.

16. Gill RC, Kellow JE, Browning C, Wingate DL. The use of intraluminal strain gauges for recording ambulant small bowel motility. Am J Physiol. 1990;258(4 Pt 1):G610-G615. 
17. Husebye E, Skar V, Aalen OO, Osnes M. Digital ambulatory manometry of the small intestine in healthy adults. Estimates of variation within and between individuals and statistical management of incomplete MMC periods. Dig Dis Sci. 1990;35:1057-1065.

18. Kellow JE, Gill RC, Wingate DL. Prolonged ambulant recordings of small bowel motility demonstrate abnormalities in the irritable bowel syndrome. Gastroenterology. 1990;98(5 Pt 1):1208-1218.

19. Jebbink RJ, vanBerge-Henegouwen GP, Akkermans LM, Smout AJ. Antroduodenal manometry: 24-hour ambulatory monitoring versus short-term stationary manometry in patients with functional dyspepsia. Eur J Gastro Hepatol. 1995;7:109-116.

20. Byrne KG, Quigley EM. Antroduodenal manometry: an evaluation of an emerging methodology. Dig Dis. 1997;15(Suppl 1):53-63.

21. Scott SM, Knowles $\mathrm{CH}$, Wang D, et al. The nocturnal jejunal migrating motor complex: defining normal ranges by study of 51 healthy adult volunteers and meta-analysis. Neurogastroenterol Motil. 2006;18:927-935.

22. Quigley EM, Deprez PH, Hellstrom P, et al. Ambulatory intestinal manometry: a consensus report on its clinical role. Dig Dis Sci. 1997;42:2395-2400.

23. Soffer EE, Thongsawat S. Small bowel manometry: short or long recording sessions? Dig Dis Sci. 1997;42:873-877.

24. Miedema BW, Schwab J, Burgess SV, Simmons JW, Metzler MH. Jejunal manometry predicts tube feeding intolerance in the postoperative period. Dig Dis Sci. 2001;46:2250-2255.

25. Stanghellini V, Cogliandro R, Cogliandro L, et al. Clinical use of manometry for the diagnosis of intestinal motor abnormalities. Dig Liver Dis. 2000;32:532-541.

26. Hyman PE, Napolitano JA, Diego A, et al. Antroduodenal manometry in the evaluation of chronic functional gastrointestinal symptoms. Pediatrics. 1990;86:39-44.

27. Vantrappen G, Coremans G, Janssens J, Mantides A, Vanden Borre F. Inversion of the slow-wave frequency gradient in symptomatic patients with Roux-en-Y anastomoses. Gastroenterology. 1991;101:1282-1288.

28. Quigley EM, Donovan JP, Lane MJ, Gallagher TF. Antroduodenal manometry. Usefulness and limitations as an outpatient study. Dig Dis Sci. 1992;37:20-28.

29. Bjornsson ES, Abrahamsson H. Contractile patterns in patients with severe chronic dyspepsia. Am J Gastroenterol. 1999;94:54-64.

30. Bharucha AE, Camilleri M, Low PA, Zinsmeister AR. Autonomic dysfunction in gastrointestinal motility disorders. Gut. 1993;34:397-401.

31. Lindberg G, Tornblom H, Iwarzon M, Nyberg B, Martin JE, Veress B. Full-thickness biopsy findings in chronic intestinal pseudoobstruction and enteric dysmotility. Gut. 2009;58:1084-1090.

32. Stanghellini V, Cogliandro RF, De Giorgio R, et al. Natural history of chronic idiopathic intestinal pseudo-obstruction in adults: a single center study. Clin Gastroenterol Hepatol. 2005;3:449-458.

33. Gorard DA, Libby GW, Farthing MJ. Ambulatory small intestinal motility in 'diarrhoea' predominant irritable bowel syndrome. Gut. 1994;35:203-210.

34. Jebbink HJ, vanBerge-Henegouwen GP, Akkermans LM, Smout AJ. Small intestinal motor abnormalities in patients with functional dyspepsia demonstrated by ambulatory manometry. Gut. 1996;38:694-700.

35. Schmidt T, Hackelsberger N, Widmer R, Meisel C, Pfeiffer A, Kaess $\mathrm{H}$. Ambulatory 24-hour jejunal motility in diarrhea-predominant irritable bowel syndrome. Scand J Gastroenterol. 1996;31:581-589.

36. Samsom M, Jebbink RJ, Akkermans LM, van Berge-Henegouwen GP, Smout AJ. Abnormalities of antroduodenal motility in type I diabetes. Diabetes Care. 1996;19:21-27.

37. Soffer E, Thongsawat S. Clinical value of duodenojejunal manometry. Its usefulness in diagnosis and management of patients with gastrointestinal symptoms. Dig Dis Sci. 1996;41:859-863.
38. Hackelsberger N, Schmidt T, Renner R, Widmer R, Pfeiffer A, Kaess $\mathrm{H}$. Ambulatory long-term jejunal manometry in diabetic patients with cardiac autonomic neuropathy. Neurogastroenterol Motil. 1997;9:77-83

39. Small PK, Loudon MA, Hau CM, Noor N, Campbell FC. Large-scale ambulatory study of postprandial jejunal motility in irritable bowel syndrome. Scand J Gastroenterol. 1997;32:39-47.

40. Wilmer A, Van Cutsem E, Andrioli A, Tack J, Coremans G, Janssens J. Ambulatory gastrojejunal manometry in severe motility-like dyspepsia: lack of correlation between dysmotility, symptoms, and gastric emptying. Gut. 1998;42:235-242.

41. Glia A, Akerlund JE, Lindberg G. Outcome of colectomy for slowtransit constipation in relation to presence of small-bowel dysmotility. Dis Colon Rectum. 2004;47:96-102.

42. Wilmer A, Andrioli A, Coremans G, Tack J, Janssens J. Ambulatory small intestinal manometry. Detailed comparison of duodenal and jejunal motor activity in healthy man. Dig Dis Sci. 1997;42:1618-1627.

43. Soffer EE, Thongsawat S, Ellerbroek S. Prolonged ambulatory duodeno-jejunal manometry in humans: normal values and gender effect. Am J Gastroenterol. 1998;93:1318-1323.

44. Seidl H, Gundling F, Pehl C, Pfeiffer A, Schepp W, Schmidt T. Small bowel motility in functional chronic constipation. Neurogastroenterol Motil. 2009;21:1278-e122.

45. Summers RW, Anuras S, Green J. Jejunal manometry patterns in health, partial intestinal obstruction, and pseudoobstruction. Gastroenterology. 1983;85:1290-1300.

46. Andrioli A, Wilmer A, Coremans G, Vandewalle J, Janssens J. Computer-supported analysis of continuous ambulatory manometric recordings in the human small bowel. Med Biol Eng Compu. 1996;34:336-343

47. Hellemans J, Joosten E, Ghoos $\mathrm{Y}$, et al. Positive ${ }^{14} \mathrm{CO}_{2}$ bile acid breath test in elderly people. Age Ageing. 1984;13:138-143.

48. Maes BD, Ghoos YF, Geypens BJ, et al. Combined carbon-13glycine/carbon-14-octanoic acid breath test to monitor gastric emptying rates of liquids and solids. J Nucl Med. 1994;35:824-831.

49. Mathias JR, Fernandez A, Sninsky CA, Clench MH, Davis RH. Nausea, vomiting, and abdominal pain after Roux-en-Y anastomosis: motility of the jejunal limb. Gastroenterology. 1985;88(1 Pt 1):101-107.

50. Smout AJ. Manometry of the gastrointestinal tract: toy or tool? Scand J Gastroenterol. 2001;36:22-28.

51. Galati JS, McKee DP, Quigley EM. Response to intraluminal gas in irritable bowel syndrome. Motility versus perception. Dig Dis Sci. 1995;40:1381-1387.

52. Corinaldesi R, Stanghellini V, Raiti C, Rea E, Salgemini R, Barbara L. Effect of chronic administration of cisapride on gastric emptying of a solid meal and on dyspeptic symptoms in patients with idiopathic gastroparesis. Gut. 1987;28:300-305.

53. Davis $\mathrm{RH}$, Clench $\mathrm{MH}$, Mathias JR. Effects of domperidone in patients with chronic unexplained upper gastrointestinal symptoms: a double-blind, placebo-controlled study. Dig Dis Sci. 1988;33:1505-1511.

54. Kellow JE, Phillips SF, Miller LJ, Zinsmeister AR. Dysmotility of the small intestine in irritable bowel syndrome. Gut. 1988;29:1236-1243.

55. Mearin F, Lacy BE, Chang L, et al. Bowel disorders. Gastroenterology. 2016;150:1393-1407e5.

56. Chini P, Toskes PP, Waseem S, Hou W, McDonald R, Moshiree B. Effect of azithromycin on small bowel motility in patients with gastrointestinal dysmotility. Scand J Gastroenterol. 2012;47:422-427.

57. Moshiree B, McDonald R, Hou W, Toskes PP. Comparison of the effect of azithromycin versus erythromycin on antroduodenal pressure profiles of patients with chronic functional gastrointestinal pain and gastroparesis. Dig Dis Sci. 2010;55:675-683. 
58. di Stefano M, Vos R, Vanuytsel T, Janssens J, Tack J. Prolonged duodenal acid perfusion and dyspeptic symptom occurrence in healthy volunteers. Neurogastroenterol Motil. 2009;21:712-e40.

59. Miedema BW, Kelly KA, Camilleri M, et al. Human gastric and jejunal transit and motility after Roux gastrojejunostomy. Gastroenterology. 1992;103:1133-1143.

60. van der Mijle HC, Kleibeuker JH, Limburg AJ, Bleichrodt RP, Beekhuis $\mathrm{H}$, van Schilfgaarde R. Manometric and scintigraphic studies of the relation between motility disturbances in the Roux limb and the Roux-en-Y syndrome. Am J Surg. 1993;166:11-17.

61. Malagelada C, Karunaratne TB, Accarino A, et al. Comparison between small bowel manometric patterns and full-thickness biopsy histopathology in severe intestinal dysmotility. Neurogastroenterol Motil. 2018;30:e13219.

62. Smout AJ. Small intestinal motility. Curr Opin Gastroenterol. 2004;20:77-81.

63. Deloose E, Janssen P, Corsetti M, et al. Intragastric infusion of denatonium benzoate attenuates interdigestive gastric motility and hunger scores in healthy female volunteers. Am J Clin Nutr. 2017;105:580-588.

64. Corsetti M, Pagliaro G, Demedts I, et al. Pan-colonic pressurizations associated with relaxation of the anal sphincter in health and disease: a new colonic motor pattern identified using high-resolution manometry. Am J Gastroenterol. 2017;112:479-489.

65. Arkwright JW, Dinning P, Deloose E, et al. The distal duodenal brake revealed by high resolution fibre optic manometry. Gastroenterology. 2017;152:S205.

How to cite this article: Ang D, Pannemans J, Vanuytsel T, Tack J. A single-center audit of the indications and clinical impact of prolonged ambulatory small intestinal manometry.

Neurogastroenterol Motil. 2018;30:e13357.

https://doi.org/10.1111/nmo.13357 